\title{
Research on the principles of user behavior in building information resource sharing system
}

\author{
Qi Wang ${ }^{\mathrm{a}}$, Wenyong Chen ${ }^{\mathrm{b}}$ \\ Library of JiLin Agriculture University, ChangChun 130118, China \\ awangqibios@163.com, bhongsepiaochong@126.com
}

\begin{abstract}
The information resource sharing system as a information movement, will guide users to access and use knowledge or information as the information commons. Many barriers existed in information sharing systems due to the less consideration of the users' behavior in information utilization by designers of the information sharing systems. Therefore, the design of information sharing systems should be fully aware of and respect for user information behaviors, and on this basis, to adhere to the design concept of the user information behavior laws in order to truly complete the mission of the information sharing systems. Otherwise, the principle of user information behaviors will most likely constitute the information sharing "regularity disorder".
\end{abstract}

Keywords:information sharing, information behaviors, information behavior laws

\section{Introduction}

Information sharing system as a knowledge or information commons, will be a main physical location of users to complete their information behaviors. To build such system, users' needs should be the driving force, users' information behaviors should be respected, users' information use behaviors should be coincided. This is the only way to get users' support and extensive use and complete the constructed mission and achieve its ultimate goal.

\section{Behavioral obstacles of users to use information resources in information commons}

At present, domestic and foreign scholars have conducted extensive research on behavioral obstacles of users using information under network environment. It is significant to summarizes those behavioral obstacles in establishment of information commons. Research by Zhang Yiyan et al. shows [1] that: behavioral obstacles of the users using information are as follow: (1) information identification obstacles, including: literature demand barriers, available information obstacles, information sources integration obstacles, information sources classification barriers, information language barriers; (2) information access barriers, including: information availability barriers, information sources response speed, information sources cost barriers, the carrier type and literature format of information sources obstacles; (3) information use 
obstacles, including: information quality barriers, information reveal accuracy barriers, information not comparable obstacles. Zhao Yalan et al. have pointed out that [2], users information obstacles under the conditions of modern technology literature information sharing, including: (1) information identify obstacles; (2) information access obstacles; (3) reading habit obstacles; (4) information screening obstacles, and so on. According to JiLin Agricultural University library's actual experience to participate in the CALIS and CASHL as well as other types of literature information resources sharing systems, users meet the following obstacles in all kinds of literature at various levels of information sharing system, including: (1) Demand obstacles, for which performance are that: resources time span covered in the system are limited, especially in the seventies and eighties and the previous literature of last century only covering relatively small amount, access to the full text of such documents is relatively difficult, update of these data is much slower, with a single document type, document delivery request fill rate is low and sometimes there is deviation in billing system(CASHL). (2) Availability obstacles, e.g. searching platform overmuch and easy to confuse, searching interface not so concise or clear, and search fields limited(CASHL). (3) Tool obstacles, such as system itself not so stable, especially the CALIS.

Users information behaviors are less considered by the designer of information commons which lead the above obstacles[3]. Therefore, to realize information sharing, users information behaviors should be fully understood and respected through information resources sharing space platform design and the principle should be insisted for meeting the mission of information sharing platform.

\section{User information behavior principle in building information resource sharing system}

\subsection{Moores Law}

Calvin Mooers-one of the pioneers of the information retrieval research, after a number of studies he found out that users will tend to not use information retrieval system if it brings more trouble to use. The law reveals the rule of users using information retrieval system. For users, the most accessible information is not the most useful information, which means the availability and validity of information is not consistent. The users select a retrieval system putting the information availability as the primary basis.

At present, the more popular understanding of the Moores law focus on the efforts of users obtain the required information in library and information science. Thus, the law can be expressed as: the more difficult using, the more time spending on an information retrieval system, the less using the information retrieval system by users. Roger K Summit, Dialog founder, express it by another way: "Moores law tells us that information using and easiness to access information are proportional." [7]

According to the law, information availability is the primary basis for designing of information retrieval and sharing systems. Therefore, the Moores law is not only the 
rule of designing information retrieval system, but also the guide of designing collection and information system.

\subsection{Zipf Law}

In 1949, linguistics professor George Kingsye Zipf, Harvard University, pointed out "minimum power-saving principle" in his book called "Human behavior and Minimum Power-saving Principle --Human Ecology Introduction" [8]. It put forward that human social activities are affected by this principle, people always hope to use the minimum cost to obtain the maximum benefit. In other words, human behavior is based on the minimum power-saving principle. In fact, this principle is using throughout the whole users information retrieval behavior. Therefore, this law should be followed in the information sharing system, the users will give up obtaining sharing information if his work intensity is too large .

It reveals two characteristics of users psychology in information sources selection: (1) The most readily available source of information is the first choice when user selects information source, and then its reliability and quality. (2)In the process of obtaining information, the user is more likely to minimize the cost of obtaining information at the expense of the information quality. Hence, there are two matters should be considered for designing information sharing system: first, those systems with cumbersome operation, too complicated path in building information commons are not viable; Second, the database of information commons must be context unified, standard terminology, semantics accurate, and expression concise, minimizing the work of understanding the information content. It should build and provide service from user perspective, then research the information commons accessibility how to influence the user requirements from the user psychology, ensure the minimum power-saving principle implementation to meet user needs.

Wang Xiaona put forward seven measures to improve the accessibility of building information commons[9]: (1) physical environment availability: the using interface should be friendly except the geographical position, and can use multimedia to guide users; (2) retrieval function and access points availability: the retrieval ways and types should be varied to fit users' different retrieval habit; (3) database availability: increase the content of the database, such as subject terms, keywords and citation, etc.; (4) system openness and interconnectedness: the system can be connected with others; (5) remote communication: exchange information to the distance; (6) users assistance: with a complete operating instructions; (7)retrieval system structure availability: promote system efficiency.

In addition, the law is also applicable to the information retrieval list compilement and information document structure designment of information resources sharing space. 


\subsection{Robin Hood Effect}

Developing with the science technology and informatization, the social members information need level has improved. Majority users' need of information tends to average, thus the information resources using also presents a trend of average. The users' information demand will be affected when the information resource is not sufficient as the Robin Hood effect. At present, the trend will be more obvious due to the network equality.

Robin Hood effect reveals two characteristics of the information resources use from the perspective of users behavior[10]: first, the users' information need must be affected if the information resources is not sufficient; Second, most users' information need level tends to average. Understanding the Robin Hood effect helps to reduce the "block" grade, break mind-set grade, and determine the priority according to the information value maximization standard in setting up information sharing space. The key users' information need should be considered priority, taking into account all users' information resources sharing power to satisfy all users' need.

\subsection{Information Absorption Limit Regulation}

Information absorption process is the process of cognitive activities between users and information. Users' information absorption includes information accepting, processing, understanding and utilizing etc. Users reaction and absorption to the information is faster following the informatization acceleration. But the users' information absorption is limited, in a certain range, when information input and absorption rate exceeds the critical value, the users' information response and absorption rate will be slower, then it will appear the information overload phenomenon, which we called information absorption limitation[11]. Generally speaking, under the certain period of time, large amount of outside information is provided to users which is far larger than the amount of information the user can absorb, users have to choose and filter those information,and to keep the most important and valuable information.

According to this regulation, designers of information commons, especially in the design of retrieval interfaces, should strictly follow users' information absorption regulation to design multi-types retrieval paths and provide related methods to avoid narrow or expanded searching result. In addition, to avoid reducing the users' distress of information accession, the design of retrieval platform classification system can be neither too professional nor too simplified [12]. 


\subsection{Information Foraging Regulation}

In the early 1990s, Peter Pirolli and Stuart Card,from California Palo Alto Research Centre (PARC) of United States, found that people's information search pattern under the network environment is similar to animal foraging strategies. They studied users' information behavior and behavior navigation of information landscape (links, description, and other data)under the network environment cooperating with psychologists, then they found that the time, money and energy of users in obtaining information and the needed information obtained needs to reach an optimal balance, like the animal foraging strategies. Thus, they put forward the information foraging theory first time, and pointed out that in the process of information searching and absorption, people should adjust their own information foraging strategy constantly to achieve maximization of information profit according to the information environment[13].

The information foraging theory has three main elements: information patches, information scent and information diet[14 to 15]. Information patches is the abundant information resource in information environment, it can be a website, a paper, a book, a web page, a document through that users search information. Information scent is the extension of information concept clues, it is a subjective assessment for contained information and required information correlation in the information resources during the process of searching information, and it plays a navigated role in information searching through some certain value or utility menu labeling, which decides the path information searching along. Users find the optimal information "patches" with the correlated information clues during searching information on the Internet.Information diet is the kind of information which users choose when they forage information. Due to the regularity of network information resources distribution it consumes scarce resource of time, money and energy when user foraging information, so user needs to select information during searching information. If the searching scope is too narrow, user may need to spend more time to build retrieval model, which makes the searching results partial; If the searching range is too expanded, user may be submerged by information retrieved again. So, in constructing information commons, we should design the information diet to conform user information behavior .

The designers have been paying attention to interface design in the information searching system design. They think the interface must be powerful, too simple interface can not customize questions according to users' need and obtain ideal results. However, actual survey showed that users prefer simple interface, people hope use patterns instead of words to increase the interface usability[9]. Henk J.Voorbij through the network information searching survey pointed: "The advanced retrieval utilization rate is very low"[16]. Bernard $\mathrm{j}$. Jansen also found in the experiment research: "Retrieval results are not obvious affected by complex questions" [17-18]. These research results show that the retrieval system designers should not have to spend energy on the theory of design advanced retrieval functions, they should focus on how to design better and related online help, how to insert the efficient automatic correction method, how to filter the search results and carry effective sorting, how to provide users with retrieval vocabulary control, etc. Jason Vaughan also pointed out: "Retrieval system designers must consider problems from users perspective.The retrieval system designers are engineers and computer scientists, they attach more 
importance to comprehensiveness and flexibility of functions, but common users have no experience on retrieval system or database, they just require the design of retrieval tools are easy to use, so there should be a bridge between the thinking ways of these two types people." [19]

\section{Conclusions}

Information commons will be a knowledge commons that is a special designed onestop service center and collaborative information sharing environment. The design of it can be based on two ideas: first is open access, second is service. Information commons needs to correspond with hommization design requirements, user information behavior principles and user information behavior regulations.

\section{Acknowledgment}

The corresponding author of this paper is Wenyong Chen. This paper is supported by the Youth Foundation of Jilin Agricultural University (Grant NO. 201337), CALIS Programs of the National Agronomy Literature Information Center(Grant NO. 2014026) .

\section{References}

1. Zhang Yiyan, Yang Yuhui. The Study of Information Process Gaps[J]. Document,Information and Knowledge, 2008, (5): 78-81.

2. Zhao Yalan, Li Ping. Analysis of the Document Information Sharing Barriers in the Conditions of Modern Technology [J]. Modern Information, 2004(2): 9-11.

3. Alan Cooper, Liu Songtao translated. About Face 3 Interactive Essence of the Design[M]. Beijing: Publishing House of Electronics Industry, 2008: 38-49. (in Chinese)

4. Seal, Robert A. The Information Commons: New Pathways to Digital Resources and Knowledge Management [C]. Reprint for the 3rd China/U.S Conference on Libraries, Shanghai, March 2005.

5. Sun Yuwei. Visualization Analysis on Knowledge Foundations, Research Hotpots and Frontiers of Information Behavior[J].Document,Information and Knowledge,2012,(1): 108116.

6. Zhang Zhiwei, Zhang Hui. Avoiding Information Sharing "Regulation Obstacles"[N]. Libration Army Daily, 2012-05-24 (7).

7. Summit R K. Roger K. Summit[J]. Online Information Review, 1991,15(3/4): 123-128.

8. Zipf G K. Human Behaviour and the Principle of Least Effort: An Introduction to Human Ecology [M]. New York: Hafner,1st ed., 1972,19-55.

9. Wang Xiaona. Accessibility of Minimum Power- saving Principle to Information Retrieval System[J].Information Science, 2000, 18(2):135-136(in Chinese) 
10. Zhou Weibin. Regularity Study of Network Information users' information needs[J]. Information Research, 2008,(3):12-14.

11. Yang $\mathrm{C} \mathrm{C}$, Chen $\mathrm{H}$, Honga $\mathrm{K}$. Visualization of large category map for Internet browsing $[\mathrm{J}]$. Decision Support Systems, 2003,35(1): 89 - 102.

12. Wu Peng, Zhang Peipei, Gan Liren. Research on the Mental Model for Website Users in the Process of Information Access[J]. Journal of the China Society for Scientific and Technical Information, 2011, 30(9):935-945.

13. Pirolli $\mathrm{P}$, Card $\mathrm{S} \mathrm{K}$. Information foraging in information access environments[C/OL]. In Proceedings of the Conference on Human Factors in Computing Systems, CHI '95. New York: Association for Computing Machinery. 1995, 51-58 [2010-07-08]. http://www.sigchi.org/chi95/proceedings/papers/ppp_bdy.htm

14. Yang Yang, Zhang Xinmin. Advance in Information Foraging Theory[J]. New Technology of Library and Information Service, 2009, (1):73-79.

15. Yang Yang,Zhang Xinmin.Empirical Research of Network Information Environment Based on Foraging Theory[J].Journal of the China Society for Scientific and Technical Information, 2010, 29(1):169-176.

16. Voorbij Henk J. Searching scientific information on the Internet: A Dutch academic user survey[J]. Journal of the American Society for Information Science, 1999, 50(7):598 - 615.

17. Jansen B J, Spink A, Saracevic T. Real life, real users, and real needs: a study and analysis of user queries on the web[J].Information Processing and Management,2000, 36(2):207-227.

18. Jansen B J.The effect of query complexity on Web searching results[J]. Information Research, Vol. 6 No. 1, October 2000. http://informationr.net/ir/6-1/paper87.html.

19. Vaughan J. Considerations in the choice of an Internet search tool[J]. Library Hi Tech, 1999, 17(1):89-106 